Department of Economics - FEA/USP

\title{
Heterogeneity in the Extraction of Labor from Labor Power and Persistence of Wage Inequality
}

\section{EDUARDO MONTE JORGE HEY MARTINS \\ JAYLSON JAIR DA SILVEIRA \\ GILBERTO TADEU LIMA}

WORKING PAPER SERIES № 2019-45 


\title{
Heterogeneity in the Extraction of Labor from Labor Power and Persistence of Wage Inequality
}

\author{
Eduardo Monte Jorge Hey Martins (eduardoheymartins@usp.br) \\ Jaylson Jair da Silveira (jaylson.silveira@ufsc.br) \\ Gilberto Tadeu Lima (giltadeu@usp.br)
}

\begin{abstract}
:
There is evidence that labor intensity is endogenous to wage compensation and that inter- and intra-industry wage differentials are non-negligible and persistent. We explore the implications of firms periodically choosing between alternative wage compensation strategies to extract labor from labor power more effectively. The frequency distribution of labor extraction strategies across firms is endogenously time-varying as driven by satisficing evolutionary dynamics that generate wage inequality as a stable long-run equilibrium under plausible conditions. Firms willing to extract more labor from labor power remunerate workers with a higher wage. Yet a larger proportion of firms following such strategy does not necessarily result in a lower (higher) unit labor cost (profit share) and hence in higher rates of profit and saving-determined output growth. The larger the proportion of firms that attempt to extract more labor from labor power by remunerating workers with a higher wage, the less these firms are successful. This result can be seen as characterizing another contradiction of the capitalist economy.
\end{abstract}

Keywords: Labor power; work intensity; wage differential; evolutionary dynamics; income Distribution; output growth.

JEL Codes: E1; 041; J31. 


\title{
Heterogeneity in the extraction of labor from labor power and persistence of wage inequality ${ }^{\star}$
}

Eduardo Monte Jorge Hey Martins ${ }^{1}$, Jaylson Jair da Silveira² ${ }^{2}$ Gilberto Tadeu Lima ${ }^{3}$

\begin{abstract}
There is evidence that labor intensity is endogenous to wage compensation and that inter- and intraindustry wage differentials are non-negligible and persistent. We explore the implications of firms periodically choosing between alternative wage compensation strategies to extract labor from labor power more effectively. The frequency distribution of labor extraction strategies across firms is endogenously time-varying as driven by satisficing evolutionary dynamics that generate wage inequality as a stable long-run equilibrium under plausible conditions. Firms willing to extract more labor from labor power remunerate workers with a higher wage. Yet a larger proportion of firms following such strategy does not necessarily result in a lower (higher) unit labor cost (profit share) and hence in higher rates of profit and saving-determined output growth. The larger the proportion of firms that attempt to extract more labor from labor power by remunerating workers with a higher wage, the less these firms are successful. This result can be seen as characterizing another contradiction of the capitalist economy.
\end{abstract}

Keywords: Labor power, work intensity, wage differential, evolutionary dynamics, income distribution, output growth

J.E.L. Classification Codes: E11, O41, J31.

\section{Introduction}

Labor productivity is arguably endogenous (among other factors) to the level of effort and intensity with which workers perform their tasks on the job. Labor effort is not exogenous, though, and there is empirical and experimental evidence on labor effort being positively affected by wage incentives. Meanwhile, there is also considerable empirical evidence on the non-negligibility and persistence of interand intra-industry wage differentials, even after controlling for observable characteristics of workers (e.g., schooling or human capital, gender and years of experience), jobs and firms.

In fact, reference can be made to some representative and motivating empirical evidence for the U.S. showing that inter-industry wage differentials do exist, are of a non-negligible magnitude, and are persistent over longer periods of time. Katz (1986) is an early detailed study finding that non-negligible wage differentials remain even when controlling for individual characteristics of workers. Katz (1986) interprets these wage differentials as difficult to explain on the basis of differences in labor quality or

^The authors are grateful to Guilherme de Oliveira and Daniel de Santana Vasconcelos for their helpful comments. Any remaining errors are our own.

Email addresses: eduardoheymartins@usp.br (Eduardo Monte Jorge Hey Martins), jaylson.silveira@ufsc.br (Jaylson Jair da Silveira), giltadeu@usp.br (Gilberto Tadeu Lima)

${ }^{1} \mathrm{MS}$ in Economics from Federal University of Santa Catarina (Brazil) and Doctoral Student in Development Economics at University of São Paulo (Brazil)

${ }^{2}$ Associate Professor in the Department of Economics at Federal University of Santa Catarina (Brazil)

${ }^{3}$ Professor in the Department of Economics at University of São Paulo (Brazil) 
differences in non-pecuniary aspects of work requiring compensating differentials. Still according to Katz (1986), the persistence of wage differentials for long time periods implies that they are not simply transitory differentials arising to facilitate the sectoral reallocation of labor. Dickens and Katz (1987) and Katz and Autor (1999) also find that there are persistent wage differences across workers even when focusing on similar workers with similar jobs. Groshen (1991) detected non-negligible and persistent wage differentials across establishments within industries even after controlling for standard covariates and individual fixed effects. Meanwhile, Carruth et al. (2004) explore the persistence of inter-industry wage differences in the U.K. in the 1991-1996 period and find that unobserved characteristics of the workers played an important role in such persistence. Caju et al. (2010) provide evidence for eight European Union countries that inter-industry wage differentials are non-negligible and persistent even when controlling for observable productive features of the workers and characteristics of the workplace.

Against this background, one of the main contributions of this paper is to suggest an explanation for persistent wage inequality based on satisficing evolutionary dynamics of labor extraction from labor power. Reasonably, our evolutionary framework based on the seminal contribution of Herbert Simon does not impose stringent requisites in terms of rationality and access to information on the part of firm-owner capitalists who periodically choose between different wage compensation strategies to extract labor from labor power more effectively. In fact, firm-owner capitalists in the model have bounded rationality and behave according to rules of thumb, and periodically revise their choice of wage compensation strategy based on satisficing relative profitability criteria having limited and localized knowledge concerning the system as a whole.

Our contribution is related to the suggestive contested exchange approach as elaborated especially in Bowles and Gintis $(1990,1993)$. This approach shows that there needs to be a labor extraction function specifying how much effective labor firms are able to obtain from a given labor input, given that the labor contract is not costlessly enforced. Insofar as the labor contract alone cannot ensure the employer that work will be performed by hired workers as desired and expected by her, the labor exchange is, as Bowles and Gintis (1990, 1993) fittingly phrase it, contested. Our contribution is also related to the gift exchange approach articulated in Akerlof (1982), which portrays the offer of employment by a firm as an offer to exchange gifts, with the worker's effort level therefore indicating the size of the reciprocal gift. In effect, there is evidence from both laboratory experiments (see, e.g., Charness, 2004, Charness and Kuhn, 2007; Fehr and Gächter, 2008; Clark et al., 2010; Gächter and Christian, 2010; Greiner et al., 2011) and field experiments (see, e.g., Gneezy and List, 2006; Bellemare and Shearer, 2009) that higher wages elicit more effort from workers. There is also evidence that wage compensation affects labor effort (see, e.g., Campbell and Kamlani, 1997; Cappelli and Chauvin, 1991; Goldsmith et al., 2000). Meanwhile, Weisskopf, Bowles and Gordon (1983) connect the value of the wage to the productivity of labor through a partial gift exchange process using data for the U.S. since the mid-1960s. The authors find that the work intensity and effort varies positively with the cost of job loss.

Moreover, we explore the implications for the functional distribution of income and output growth of firms possibly using different wage compensation strategies to extract labor from the labor power of (and hence to obtain labor productivity from) their hired workers more effectively. The frequency distribution of the available labor extraction strategies across firms is endogenously time-varying as driven by satisficing evolutionary dynamics that may generate wage inequality as a long-run equilibrium outcome. Arguably, this analytical result is in keeping with the empirical evidence on the persistence of wage differentials.

In the model herein, firms willing to extract more labor from labor power compensate hired workers with a higher instead of lower conventional wage. Nonetheless, it is possible that a larger proportion of firms following such labor extraction strategy featuring the payment of the higher conventional wage does not necessarily generate a lower (higher) unit labor cost (profit share) and hence higher rates of 
profit and savings-determined output growth. In fact, the possibility that the larger the proportion of firms that attempt to extract more labor from labor power, the less each of these firms will succeed can be seen as characterizing another essential contradiction of capitalism. This possibility arises owing to the existence of strategic substitutability in the choice of the labor extraction compensation mechanism featuring the payment of the higher conventional wage.

As in Silveira and Lima (2016), changes in the average values of the real wage and labor productivity induced by composition effects impact on income distribution and output growth, but the two contributions differ substantially from each other in several key respects. As regards microeconomic diversity, while the model in Silveira and Lima (2016) features imperfectly-competitive firms setting prices by applying on unit labor costs possibly heterogeneous markups, the model herein is populated by pricetaking firms facing a single output price. In Silveira and Lima (2016) the available capital and the ratio of potential output to capital are homogeneous across firms, while in the model set forth here both the available capital and the output to capital ratio are heterogeneously distributed in the population of firms. Reasonably, in both contributions all firms are assumed to periodically revise (and possibly switch) their choice of wage compensation strategy based on profitability criteria, but the boundedly rational way they do so is quite different in each case. While in Silveira and Lima (2016) such individual revision process results in an evolutionary replicator dynamic for the frequency distribution of wage compensation strategies across firms, in the model of this paper all firms follow an evolutionary strategy revision protocol based on the suggestive formulation of satisficing choice behavior elaborated by Herbert Simon. As far as the macroeconomic dimension is concerned, in Silveira and Lima (2016) firms produce according to effective demand, the aggregate level of which is uniformly distributed across firms. As aggregate effective demand is assumed to be insufficient for firms to produce at full capacity utilization at the prevailing price level, the uniform rate of capacity utilization performs as adjusting variable in the product market equilibrium. In the model herein, meanwhile, an individual firm does not face effective demand problems and is able to sell profitably (but not necessarily with the highest possible or even a satisficing profitability) all the output production allowed by its available capital, which is the binding constraint (as labor is always in excess supply). Moreover, given that both the available capital and the output to capital ratio are heterogeneously distributed in the population of firms, the so-constrained output production is also heterogeneous across firms.

The remainder of the paper is organized as follows. Section 2 contains a conceptual prelude on labor extraction from labor power and describes the substance of the model, while Section 3 presents the structure of the model and its behavior in the short run. Section 4 develops the satisficing evolutionary dynamics that endogenously drive the frequency distribution of labor extraction wage compensation strategies and explores the behavior of the model in the long run. The final section summarizes the main analytical results derived along the way.

\section{Conceptual prelude and substance of the model}

The model set forth in this paper draws conceptually on the relevant contribution to a microfoundation framework for political economy offered especially in Gintis (1976), Bowles (1985) and Bowles and Gintis $(1990,1993)$. In this contribution the exercise of power features prominently as a mechanism for the enforcement of the competing distributional interests often involved in a market exchange. In fact, when the contract associated with a market exchange is comprehensive and enforceable at no (or a negligible) cost to the exchanging parties, the regulation of such contract is feasibly subject to an exogenous claim enforcement through a third party (typically the state). However, this process of regulation of the contract requires the market exchange to be transparent enough in the sense that the characteristics of what is being exchanged are readily, clearly and certainly determined. This way any contractual 
transgressions are likewise readily, clearly and certainly detected and redressed, even if ultimately by resorting to the courts.

Meanwhile, when some aspect of what is being exchanged is either complex or hard to monitor to the point that it is not readily, clearly and certainly determined, it follows that a comprehensive contract is not feasible or enforceable by a third party. In this case, the exogenous claim enforcement of the competing distributional interests involved in and regulated by the contract cannot be secured. The effective terms of the exchange regulated by such contract then result at least in part from the sanctions, surveillance, and other enforcement activities deliberately adopted by the parties to the exchange themselves. Bowles and Gintis (1990) appropriately refer to this process of regulation of the contract by the parties to the contract themselves as endogenous claim enforcement. Relatedly, a market exchange requiring the exchanging parties to implement endogenous claim enforcement strategies themselves is termed a contested exchange by the authors.

According to Bowles and Gintis (1990), the labor exchange is an archetypal example of a key market exchange in a capitalist economy which inevitably involves endogenous instead of exogenous claim enforcement. The labor exchange is invariably a contested exchange in that the worker's labor service (or power) includes a key feature (intensity of work) that is not fully specified in a costlessly enforceable labor contract. As recalled by the authors, a fundamental aspect of Marx's concept of labor is that, in the labor exchange, the employer compensates the worker with a wage in return for the worker's formal submission to the firm's authority. Nevertheless, the performance of work itself is neither assured in the labor contract nor can be enforced by the state or any other external party. ${ }^{4}$ Given that labor has to be extracted from the worker by whatever legal mechanisms the employer is able to devise and implement, the enforcement of the actual terms of the labor contract (dubbed the extraction of labor from labor power by Marx) is unavoidably endogenous. Thus, the labor exchange is contested in that it includes the intensity of work as a contested feature of the labor process measurable only imperfectly or at considerable cost by the employer.

An employment relationship is formed when, in return for a wage compensation, the worker accepts to surrender to the authority of the employer. Yet a worker's promise to deliver a satisfactory level of intensity of work on the job, even if made with the resolute intention of honoring it, is not legally enforceable. In fact, the intensity of work as a key feature of the labor contract is costly for the worker, valuable to the employer, and costly to monitor and measure by either the employer or any third party. As a case in point of a contested exchange, the employment relationship invariably relies on endogenous enforcement mechanisms implemented by the employer, not the state, for ensuring the provision of any particular level of intensity of work by workers (Gintis, 1976; Bowles, 1985). ${ }^{5}$

As in other contested exchanges, in the labor exchange the actual terms of exchange are crucially determined by the monitoring, sanctioning and incentivizing mechanisms implemented by one party to induce the other party to provide the desired level of the contested attribute. Bowles and Gintis (1990) emphasize one extremely important endogenous enforcement mechanism available to the employer: contingent renewal. When applied to a labor exchange, this obtains when the employer elicits intensity of

\footnotetext{
4 "Labor-power is a commodity whose material attributes include the capacity to perform certain types and intensities of productive activity. Labor itself, however, is the active, concrete, living process carried on by the worker; its expression is determined not only by labor-power but also by the ability of the capitalist to exploit it." (Gintis, 1976, p. 37)

5 "The labor exchange involves the exchange of one commodity (labor-power) for another (the wage). But the concrete substance of labor which actually enters into the production process is conceptually distinct from labor-power and must be analyzed in fundamentally different terms. Actual labor is not exchanged for a wage according to market principles. Thus power relations between capitalist and worker are resultants of economic organization, and cannot be taken as given prior to economic analysis." (Gintis, 1976, p. 42, original emphasis)
} 
work from the worker by promising to renew the contract in future periods if satisfied and to terminate the contract if not.

The implementation of an endogenous enforcement mechanism is typically costly to the employer. Bowles and Gintis (1990) refer to the employment rent (or the cost of job loss to the worker) associated with the labor contract as the excess of the wage over the fallback position of the worker. They dub this a rent as it represents a payment above and beyond the income of an identical worker without the job. In fact, as the cost of job loss to the worker varies positively with the received wage, raising the threat of job loss by increasing the paid wage is feasible to some extent but costly to the employer. Admittedly, the cost of job loss to the worker also varies (now negatively) with the probability of reemployment and any alternative income such as unemployment insurance, but these other determinants of the employment rent are typically beyond the reach of the employer's decision making and therefore not affected by it.

As a contested exchange, therefore, the labor exchange requires the employer to implement endogenous enforcement strategies to elicit a desired level of intensity of work from the worker. Yet an employer's claim against the intensity of the work performed by the worker is a prime example of asset entailing endogenous enforcement costs. Accordingly, the labor market not only allocates workers to jobs, but it also configures an environment governing the costly regulation of the quality and pace of work (Bowles and Gintis, 1993). In the model set forth in this paper, we build on this perceptive understanding of the labor market to further specify it as an environment subject to evolutionary dynamics. As pointed out in Gintis (1976), the necessity of extracting labor from labor power more effectively by means of appropriate enforcement of the labor exchange impacts a great deal on the capitalist's choice, for instance, of a wage structure. In fact, as observed in Bowles and Gintis (1993), given that the labor exchange is a contested exchange which is durable and personal, the employer has an interest in shaping the structure of the exchange to mold the worker's behavior as regards, for instance, her intensity of work by offering a higher wage or job security.

The model herein features the payment of a higher instead of lower conventional wage (with the possibility of renewal of the labor contract in the next production period, as elaborated later) to elicit intensity of work more effectively as an endogenous enforcement strategy. In fact, these two wage compensation strategies can be interpreted as alternative endogenous enforcement strategies in that they both offer an enforcement rent, with the higher wage strategy of course yielding a higher enforcement rent. Labor exchange is a contested exchange that takes place in an environment featuring firms periodically revising (and possibly switching) their choice of wage compensation strategy as endogenous claim enforcement strategy. This gives rise to evolutionary dynamics of strategy revision which will crucially impact on the dynamics of the average conventional wage and the functional distribution of income and hence the rate of output growth.

In our model, labor is observationally homogeneous, the employed and unemployed are otherwise undifferentiated, and workers have complete information about job and wage conditions throughout the economy. Yet the offering of either the higher or the lower conventional wage is a take-it-or-leave-it offer under conditions of permanent excess supply of labor (given the considerable largeness of Marx's familiar reserve army of the unemployed). For an individual worker, therefore, the alternative to accepting a given wage offer is to rejoin the large reserve army of labor and therefore face the negligible probability of receiving another job offer. To put it differently, with the payment of either the higher or the lower conventional wage the worker receives an employment rent, the value of which is nonetheless directly proportional to the value of the wage received. After all, as further elaborated later, the employment rent has to strictly positive for a strategy of contingent renewal of the labor contract by the employer to be effective.

As observed in Bowles and Gintis (1993), the contested nature of the exchange in the labor market 
involves both the worker and the employer behaving strategically when repeatedly interacting with each other. This strategic behavior involves the worker and the employer acting on the recognition that the benefit that each one of them will reap from the labor exchange depends not only on their individual actions, but also on those of the other party to the exchange. Therefore, it is only reasonable on behavioral grounds to assume that firms periodically revise their choice of labor extraction strategy based on relative profitability criteria. Interestingly, this creates another form of strategic interaction, but now across employers: how profitable is the wage compensation strategy an individual employer chose to follow depends on the same choice made by the other employers. As described in the next section, given that the resulting externalities are not internalized by employers, there is a strategic substitutability in the employers' choice of labor extraction strategy which configures another contradiction of capitalism: the higher the proportion of employers who follow the higher wage strategy expecting to extract labor from labor power more effectively than otherwise, the lower the extent to which each one will succeed.

According to Bowles and Gintis (1993), a salient feature of a contested exchange labor market is that the cost of job loss to the worker (which equals the value of the job to the worker less the expected value of the next best alternative) configures an enforcement rent. The reason is that the fear of losing the job ensures a higher level of intensity of work than the worker would deliver in the absence of such a rent. In our model, given that firms may choose to compensate workers with either a lower or higher conventional wage, the cost of job loss and the associated employment rent across hired workers may be heterogeneous.

Bowles and Gintis (1990) alternatively refer to the employment rent (or the cost of job loss) as the excess of the wage over the income of an identical worker without the job. In the model set forth in this paper, the possibility exists that an identical worker without a job in a firm following a certain wage compensation strategy has a job in a firm following the other wage compensation strategy. Yet the largeness of the reserve army of unemployed workers implies that the expected value of the next best alternative is always strictly much lower than the received wage even for workers compensated with the lower conventional wage. ${ }^{6}$

It follows that the payment of the higher conventional wage by the firm (with the possibility of renewal of the labor contract) can be interpreted as a labor extraction strategy of attaching a higher employment rent to the job. Yet the extent to which the higher wage strategy will ensure the extraction of more labor from labor power than the lower wage strategy is endogenous as it varies positively with the excess of the higher wage over the (weighted) average wage across firms. In effect, such average wage is seen by the worker hired by a higher wage firm as an estimate of which could alternatively had been the wage offer she received. Given that such an estimate is a key determinant of the intensity of the work elicited by the higher wage, the extent to which the higher wage strategy will be more effective than the lower wage strategy as labor extraction strategy depends on the frequency distribution of wage strategies across firms, which is endogenously time-varying as driven by satisficing evolutionary dynamics.

Therefore, the employment rent is a kind of enforcement rent. As argued in Bowles and Gintis (1993), where pairs of agents engage in repeated transactions, as it is the case with employers and workers, the terms of exchange often include a payment in excess of at least one agent's next best alternative. This enforcement rent is required for the threat to terminate the relationship to succeed in enforcing the terms of exchange. Bowles and Gintis (1993) term a contingent renewal strategy the offering of an enforcement rent to an exchange partner, one using the threat of termination to ensure compliance. When it comes to a contested exchange in the labor market, the wage is counted by the employer as a costly mechanism

\footnotetext{
${ }^{6}$ As noted by Joan Robinson, "the misery of being exploited by capitalists is nothing compared to the misery of not being exploited at all." (1964, p. 46)
} 
of endogenous enforcement of claims against work intensity, the reason being that the enforcement rent and the resulting the cost of job loss vary positively with the wage.

As argued earlier, the payment of either the higher or the lower wage (with the possibility of renewal of the labor contract in either case) can be interpreted as alternative endogenous enforcement strategies. Although these conventional wages are exogenously given constants, both strategies are effective in that by following any of them the firm will extract labor from labor power as specified in our model. More precisely, firms compensating workers with the lower wage will extract an exogenously given constant amount of labor (or labor productivity) from the hired labor power. Meanwhile, firms paying the higher wage will extract an amount of labor (or labor productivity) from the hired labor power which is higher than that extracted by firms paying the lower wage in an extent that varies positively with the excess of the higher wage over the weighted average wage across firms.

As our model conceives of the labor exchange as a contested exchange, the payment of either the higher or the lower wage is equivalent to the offering of either a higher or lower enforcement rent, in either case using the threat of termination of the labor contract to ensure compliance. Borrowing the terminology used in Bowles and Gintis (1990, 1993), as described earlier, the alternative wage compensation strategies considered in our model constitute alternative contingent renewal strategies. However, we refer to these wage compensation strategies as evolutionarily contingent renewal strategies. They are evolutionarily contingent in the sense that in both of them the termination of the labor contract in the end of a given production period may result not from the firm being unable to extract as much labor from the hired labor power as it expected to, but from the firm having decided to switch wage compensation strategy in light of the realized profitability. This decision, in turn, is based on a strategy revision protocol in the spirit of the contributions of Herbert Simon centered on the notion of satisficing choice. Both wage compensation strategies offer the worker the prospect of renewal of the labor contract for the next production period at a wage which nonetheless can be the same, higher (in the case of the lower wage strategy) or lower (in the case of the higher wage strategy).

Therefore, a firm following the higher wage strategy may not renew the labor contract of a given worker for the next production period (or may offer to renew it at the lower wage) even if in the current production period such worker has delivered a great deal of work intensity. The reason is that even in this case the following of the higher wage strategy to extract labor from labor power may not yield a satisficing level of profitability for the firm in question. Meanwhile, given that the extraction of labor from the hired labor power varies positively with the excess of the higher wage over the weighted average wage across firms, the extraction of labor by (and the resulting profitability of) an individual higher wage firm will vary even if such firm decides to keep following the higher wage strategy but the proportion of firms which follow the same strategy varies.

The renewal of the labor contract by the firm is of course also conditional on the demand for labor implied by its output production. In our model, the output to capital ratio is heterogeneous in the population of firms (but such heterogeneity is parametric and the average value of the output to capital ratio across firms is therefore constant). Firms do not face effective demand (or realization) problems when selling their output production, so that they fully utilize their capital capacity, which is the binding constraint on output production. Although the extraction of labor from labor power (or labor productivity) is constant in lower wage firms and variable in higher wage firms, the reserve army of the unemployed is always large enough to ensure that labor is not a binding constraint on output production.

As the output to capital ratio is heterogeneous across firms, output production is also heterogeneous across firms. The profit share is heterogeneous across firms following different labor extraction strategies but it is nonetheless homogeneous across firms following the same labor extraction strategy, so that the level of profits is heterogeneous in the population of firms. Workers do not save, whereas all firms save and automatically invest the same proportion of their heterogeneous amount of profits, so 
that capital accumulation is heterogeneous in the population on firms. Consequently, given that the profit share is homogeneous across firms following the same labor extraction strategy, but it is instead heterogeneous across firms following different labor extraction strategies, whereas the output to capital ratio is heterogeneous in the population of firms, it follows that the profit rate is also heterogeneous in the population of firms.

Although the renewal of the labor contract by the firm is conditional on the demand for labor implied by its output production, which ultimately depends on its capital stock and choice of wage compensation strategy, the firm can still use the threat to terminate the relationship (by not renewing the labor contract) to enforce the terms of labor exchange and extract as much labor from labor power as specified in the model. Consider the case of an individual higher wage firm which decides to keep following the same strategy in the next production period, and recall that the average extraction of labor productivity by higher wage firms falls with the proportion of firms following the same strategy. If the proportion of higher wage firms rises (remains the same), in the next production period labor productivity in higher wage firms will be lower (remain the same), so that labor demand by such higher wage firm will unambiguously rise (recall from earlier that the capital stock of all firms, and hence their output production, continuously rise overtime). In this situation, all the workers who delivered the level of work intensity specified in the model will have their labor contract renewed (and we assume that all additional workers needed will be randomly chosen from the large reserve army of the unemployed to receive a take-it-or-leave-it offer and will accept such an offer as it embodies the highest possible employment rent).

But suppose that the proportion of higher wage firms falls, so that in the next production period labor productivity in higher wage firms will be higher (and will be the higher, the larger the fall in the proportion of higher wage firms). In this case, the demand for labor by the higher wage firm under consideration may rise, fall or remain the same (as output production is heterogeneous across firms, such ambiguity varies across higher wage firms). If the demand for labor placed by such individual higher wage firm falls, not all of its hired workers who delivered the level of work intensity specified in the model will have their labor contract renewed. In this situation, we assume that workers whose labor contract are not renewed are randomly chosen and join the large reserve army of the unemployed. However, as output production by a given firm is always strictly positive, at least part of the workers hired by the individual higher wage firm under consideration will have their labor contract renewed. Although workers hired by a higher wage firm are aware that such a fall in the firm's demand for labor is a contingency which may materialize, we assume that they conservatively balance the whole situation in a way that lead them to deliver the level of work intensity indicated by the labor extraction function specified in our model.

Now suppose that the considered individual higher wage firm decides to switch to the lower wage strategy in the next production period. In this situation, its extraction of labor productivity will fall, so that its demand for labor will unambiguously rise. We assume that when this contingency materializes, workers hired by such individual higher wage firm will accept the offer to renew the labor contract at the lower wage, as they consider it a better alternative than to join the large reserve army of the unemployed and wait for a job offer by another higher wage firm. We also assume that all additional workers needed by this switching higher wage firm will be randomly chosen from the large reserve army of the unemployed to receive a take-it-or-leave-it offer and will accept such an offer as it embodies a strictly positive (even if not the highest possible) employment rent.

Now consider the case of an individual lower wage firm which decides to keep following the same strategy in the next production period, and recall that the average extraction of labor productivity by lower wage is homogeneous and constant across lower wage firms. In this situation, labor demand by such individual lower wage firm will unambiguously rise, so that all the workers who delivered the level 
of work intensity specified in the model will be offered the possibility of renewing the labor contract. We assume that when this contingency materializes, all workers hired by the lower wage firm under consideration will accept the offer to renew the labor contract, as they consider it a better alternative than to join the large reserve army of the unemployed and wait for a job offer by a higher wage firm. We also assume that all additional workers needed by such individual lower wage firm will be randomly chosen from the large reserve army of the unemployed to receive a take-it-or-leave-it offer and will accept such an offer as it embodies a strictly positive (even if not the highest possible) employment rent.

Finally, suppose that the considered individual lower wage firm decides to switch to the higher wage strategy in the next production period, so that labor productivity in it will be higher (and will be the higher, the lower the proportion of higher wage firms). In this case, the demand for labor placed by such individual lower wage firm may rise, fall or remain the same (and as output production is heterogeneous across firms, such ambiguity varies accross lower wage firms). If the demand for labor placed by the considered lower wage firm does not fall, all its hired workers will be offered the possibility of a renewal of the labor contract at the higher wage, and will of course accept it (and the same job offer will also be accepted by all the additional workers hired by such individual lower wage firm). Meanwhile, if the demand for labor placed by such switching lower wage firm falls, not all of its hired workers who delivered the level of work intensity specified in the model will have their labor contract renewed. In this situation, we assume that workers whose labor contract are not renewed are randomly chosen and join the large reserve army of the unemployed. However, as output production by a given firm is always strictly positive, at least part of the workers hired by such switching lower wage firm will have their labor contract renewed at the higher wage. Although workers hired by lower wage firms are aware that such a fall in the firm's demand for labor is a contingency which may materialize, we assume that they conservatively balance the whole situation (especially the possibility of a renewal of the labor contract at the higher wage) in a way that lead them to deliver the level of work intensity indicated by the labor extraction function specified in our model.

\section{Structure of the model and its behavior in the short run}

The economy is closed and features no government activities, producing a single (homogeneous) good that serves both investment and consumption purposes. Output production is carried out by a large (and fixed) population of firms, which combine two (physically homogeneous) factors of production, capital and labor, by means of a fixed-coefficient production technology. Firms produce the single good without facing either labor constraints (as there is always an accomodating industrial reserve army of labor) or realization (or effective demand) problems, thereby being able to sell profitably all output produced at the prevailing price level, which is exogenously given. Thus, we simplify matters by casting the model in real terms.

Firms are homogeneous except with respect to the strategy to extract labor from labor power they choose to follow in a given production period, which determines the conventional wage they are willing to pay (and workers, who are always in excess supply, are compelled to accept to avoid having no wage income at all). This choice of wage compensation strategy, however, is made by firms in a decentralized and uncoordinated way. In attempting to extract labor from labor power more effectively, an individual firm chooses periodically between compensating workers with a lower conventional wage $w_{\ell} \in \mathbb{R}_{++}$or a higher conventional wage $w_{h}>w_{\ell}$. A firm that chooses to offer a higher conventional wage is dubbed $h$-firm, while a firm that chooses to offer a lower conventional wage is dubbed $\ell$-firm. In a given period $t$, therefore, there is a proportion $\lambda_{t} \in[0,1] \subset \mathbb{R}$ of $h$-firms and a proportion $1-\lambda_{t}$ of $\ell$-firms. A $h$-firm is willing to follow a higher wage strategy based on the expectation that the resulting extraction of labor will be sufficiently higher than otherwise. In fact, although labor extraction (and hence labor 
productivity) is homogeneous across workers in firms following a particular labor extraction strategy, it is heterogeneous across firms following different labor extraction strategies, with the intensity of work being actually higher in $h$-firms. However, the extent to which an individual $h$-firm will succeed in extracting more labor from labor power (and hence in producing output with higher labor productivity) than behaving alternatively as a $\ell$-firm is endogenous to the frequency distribution of labor extraction strategies across firms. Such frequency distribution, in turn, is given in a period $t$ but varies over time in an evolutionary manner according to the relative profitability performance of the two available labor extraction strategies.

To keep the sharp focus on the dynamics of the frequency distribution of labor extraction compensation strategies and their implications for the functional distribution of income and thereby output growth, we simplify matters by assuming that the conventional wages $w_{\ell}$ and $w_{h}$ remain constant over time. The distribution of labor extraction compensation strategies across firms, $\left(\lambda_{t}, 1-\lambda_{t}\right)$, which is given in the short run as a result from previous dynamics, changes beyond the short run according to an evolutionary dynamic to be specified later. In the short run, for given values of the conventional wages $w_{\ell}$ and $w_{h}$, the labor extraction (and hence labor productivity) differential, the frequency distribution of labor extraction strategies across firms and, therefore, the individual and average profit shares, the short-run value of the rate of output growth is then determined. As the economy evolves towards the long run, endogenous changes in the frequency distribution of labor extraction strategies and the labor extraction (labor productivity) differential, by leading to changes in the average share of profits, causes changes in the short-run value of the rate of output growth.

Based on the conceptual prelude on the extraction of labor from labor power contained in the preceding section, we formally define the labor extraction (or labor productivity) differential $\alpha>1$ in a given period $t$ as follows:

$$
\alpha_{t} \equiv \frac{a_{h}}{a_{\ell}}
$$

where $a_{\tau} \equiv \frac{X_{\tau, t}^{i}}{L_{\tau, t}^{i}}$ denotes the labor extraction (labor productivity) of the $i$-th firm of type $\tau=h, l, X_{\tau, t}^{i}$ is the total output of the $i$-th firm of type $\tau=h, l$ and $L_{\tau, t}^{i}$ is the total employment of the $i$-th firm of type $\tau=h, l$ at period $t$. For simplicity, we assume that the labor extraction in $\ell$-firms is constant.

We use a weighted geometric average of the conventional wage in a given period $t$ (as given by $\left.w_{h}^{\lambda_{t}} w_{\ell}^{1-\lambda_{t}}\right)$ to represent the differential between the higher conventional wage and the average conventional wage, which can then be written as $\frac{w_{h}}{w_{h}^{\lambda_{t}} w_{\ell}^{1-\lambda_{t}}}=\left(\frac{w_{h}}{w_{\ell}}\right)^{1-\lambda_{t}}$ for all $\lambda_{t} \in[0,1] \subset \mathbb{R}$. In light of the discussion in the preceding section, it is conceptually and empirically reasonable to assume that the labor extraction differential varies positively with the differential between the higher conventional wage and the average conventional wage, so that the resulting labor productivity differential can be expressed as:

$$
\alpha_{t}=f\left(w^{1-\lambda_{t}}\right)
$$

with $w \equiv \frac{w_{h}}{w_{\ell}}$ and $f^{\prime}(\cdot)>0$ for all $\lambda_{t} \in[0,1] \subset \mathbb{R}$.

This specification of the additional extraction of labor from labor power obtained by firms paying the higher wage can be further substantiated as follows. First, it is conceivable that a worker who is offered the higher conventional wage reasonably sees the average conventional wage as a reliable estimate of what other conventional wage she could had been offered instead. Thus, a worker who is offered the higher conventional wage can be seen as performing her labor tasks with an additional intensity (relatively to the level of intensity she would deliver if offered the lower conventional wage) that varies positively with 
the excess of such higher conventional wage over her respective estimate of the conventional wage she could had been offered instead. Relatedly, it is plausible that the average conventional wage is seen by an employed worker as the relevant reference point against which the higher conventional wage offer should be compared when deciding how much above-reference intensity of work is justified or even required to keep such better-paid job. Therefore, an above-average conventional wage is reasonably interpreted by an employed worker as either justifying or even requiring the provision of an above-reference intensity of work. Alternatively, such reference point represented by the average conventional wage can plausibly be taken as embodying a prospective employed worker's wage expectation under uncertainty. As a result, the realization of being offered the higher conventional wage is taken as a positive surprise justifying or even requiring the provision of an above-reference intensity of work. In effect, there is experimental evidence from expectation-based reference-dependent models of workers' performance on the job that labor effort provision varies positively with the worker's wage expectation (e.g., Abeler et al., 2011).

It is worthy noting an important implication of the labor extraction differential function in (2) for the effectiveness of the higher wage strategy to further extract labor from labor power. It turns out that the greater the proportion of $h$-firms in a given short run, the smaller the positive labor extraction differential between $h$-firms and $\ell$-firms in that period, which means that an individual firm's decision to follow the labor extraction strategy featuring the payment of the higher wage in a given period has a negative payoff externality on all other $h$-firms. Therefore, there is strategic substitutability in the firms' choice of the labor extraction mechanism featuring the compensation with the higher wage.

Suppose that the labor extraction differential function in (2) assumes the linear form given by $\alpha_{t}=A w^{1-\lambda_{t}}$, where $A>1$ is a parametric constant. For analytical convenience and without any loss of generality, we set $A=w^{\beta}$, where $\beta \in(0,1) \subset \mathbb{R}$ is a parametric constant. Consequently, the additional labor extraction function can be rewritten as:

$$
\alpha_{t}=w^{\beta+1-\lambda_{t}} .
$$

We further assume that $w_{\ell}<a_{\ell}<a_{h}$ and $w_{h}<a_{h}$ to reasonably ensure that the adoption of any of the available labor extraction compensation strategies will yield a strictly positive surplus output to be appropriated as profit. In fact, the satisfaction of these inequalities ensures that the shares in output accruing to capital and labor, either for a given firm or labor extraction strategy or even the economy as whole, will remain in the interval $(0,1) \subset \mathbb{R}$.

Note that if all firms adopt the higher conventional wage strategy $\left(\lambda_{t}=1\right)$, it follows that $w^{\beta+1-\lambda_{t}}=$ $w^{\beta}$. Meanwhile, if all firms adopt the lower conventional wage strategy $\left(\lambda_{t}=0\right)$, the additional labor extraction function takes its maximum value given by $w^{\beta+1-\lambda_{t}}=w^{\beta+1}$. In this case, a lower wage firm that switches worker compensation to the higher wage mode is able to reap the largest possible additional labor extraction gain given by $w^{\beta+1}$. In order to better convey the substance of all these properties of the labor extraction differential function in (3), especially the monotonic fall in the labor extraction (or labor productivity) differential as the proportion of h-wage firms rises, they are all represented in Figure 1 .

The total real profits of each type of firm is given by:

$$
R_{h, t}^{i} \equiv X_{h, t}^{i}-w_{h} L_{h, t}^{i}=\left(1-\frac{w_{h}}{a_{h}}\right) X_{h, t}^{i}=\left(1-u_{h, t}\right) X_{h, t}^{i}
$$

and:

$$
R_{\ell, t}^{i} \equiv X_{\ell, t}^{i}-w_{\ell} L_{\ell, t}^{i}=\left(1-\frac{w_{\ell}}{a_{\ell}}\right) X_{\ell, t}^{i}=\left(1-u_{\ell}\right) X_{\ell, t}^{i}
$$




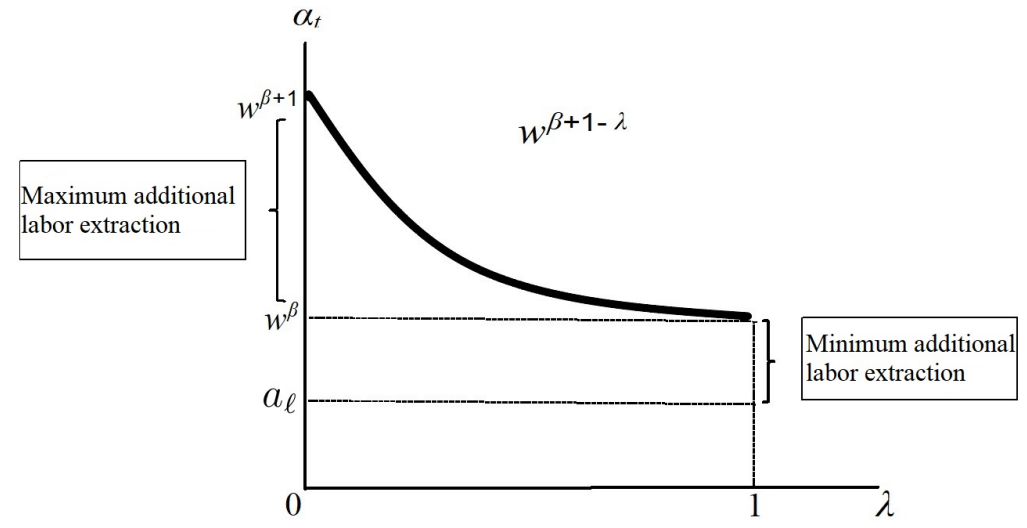

Figure 1: Additional labor extraction as a function of the frequency distribution of labor extraction strategies

where $u_{\tau} \equiv \frac{w_{\tau}}{a_{\tau}}$ is the wage share in output (or unit labor cost) of the $i$-th firm of type $\tau=h, \ell$. Given that we have assumed that both $w_{l}$ and $a_{l}$ remain constant, the wage share in $\ell$-firms, $u_{\ell}$, remains constant as well. Therefore, henceforth we will cease attaching a time subscript $t$ to the wage share in $\ell$-firms.

Considering (4) and (5), the profit share in ouput in $h$-firms and $\ell$-firms are given, respectively, by:

$$
\pi_{h, t} \equiv \frac{R_{h}^{i}}{X_{h}^{i}}=1-\frac{w_{h}}{a_{h}}=1-u_{h, t}
$$

and:

$$
\pi_{\ell} \equiv \frac{R_{\ell}^{i}}{X_{\ell}^{i}}=1-u_{\ell} .
$$

Recalling that $w \equiv w_{h, t} / w_{\ell}$ and considering (1) and (3), we can re-write (6) as follows:

$$
\pi_{h, t}=1-\frac{w_{\ell}}{a_{\ell}} \frac{w}{\alpha_{t}}=1-u_{\ell} w^{\lambda_{t}-\beta} \equiv \pi_{h}\left(\lambda_{t}\right)
$$

Therefore, while the (uniform) profit share in $\ell$-firms remains constant, the short-run value of the (uniform) profit share in $h$-firms varies negatively with the proportion of $h$-firms. The intuition underlying this result, as anticipated earlier, is that there is strategic substitutability in the firms' choice of the labor extraction compensation mechanism featuring the payment of the higher wage: the greater the proportion of $h$-firms, the smaller the differential between the higher conventional wage and the average conventional wage and, consequently, the smaller the positive labor extraction differential between $h$-firms and $\ell$-firms. In this context, the negative payoff externality that an individual firm which decides to follow the labor extraction strategy involving the payment of the higher wage imposes on all the other $h$-firms can be interpreted as another contradiction of capitalism. Interestingly, in fact, the higher the proportion of firms that attempt to extract more labor from labor power than other firms by paying a higher conventional wage, the less each of these firms will succeed in such an attempt. As we will demonstrate later, however, if the proportion of higher wage firms is low enough, a rise in such proportion, despite yielding a lower additional extraction of labor from labor power by (and hence a 
lower profit share for) these firms, will nonetheless result in a higher average profit share in income.

The conditional expected value of the profit share $\pi_{t}$ in a given period $t$, given the type $\tau$, can be expressed as:

$$
E\left(\pi_{t} \mid \tau\right)=\left\{\begin{array}{l}
\pi_{h}\left(\lambda_{t}\right), \text { if } \tau=h, \\
\pi_{\ell}, \text { if } \tau=l .
\end{array}\right.
$$

Based on the law of iterated expectations and the conditional expectation in the equation above, the short-run average profit share, $\bar{\pi}_{t}$, can be established as the expected profit share in the short run for a given frequency distribution of labor extraction compensation strategies across firms:

$$
\begin{aligned}
\bar{\pi}_{t} & =E\left[E\left(\pi_{t} \mid \tau\right)\right]=\lambda_{t} E\left(\pi_{t} \mid \tau=h\right)+\left(1-\lambda_{t}\right) E\left(\pi_{t} \mid \tau=l\right) \\
& =\lambda_{t} \pi_{h}\left(\lambda_{t}\right)+\left(1-\lambda_{t}\right) \pi_{\ell} \equiv \bar{\pi}\left(\lambda_{t}\right) .
\end{aligned}
$$

Drawing on Silveira and Lima (2017), we assume that there is heterogeneity in individual stocks of capital across firms. Let $k^{i} \equiv \frac{X_{\tau}^{i}}{K_{\tau}^{i}}$ be the individual output to capital ratio of the $i$-th firm of type $\tau=h, l$, where $K_{\tau}^{i}$ is the respective capital stock. We assume that these individual ratios remain constant when firms switch labor extraction compensation strategy. Using (4), (5), (7) and (8), the short-run profit rate associated with each labor extraction strategy is given by:

$$
r_{\tau, t}^{i} \equiv \frac{R_{\tau, t}^{i}}{K_{\tau, t}^{i}}=\left\{\begin{array}{l}
\pi_{h}\left(\lambda_{t}\right) k^{i}=\left(1-u_{\ell} w^{\lambda_{t}-\beta}\right) k^{i}, \text { if } \tau=h, \\
\pi_{\ell} k^{i}=\left(1-u_{\ell}\right) k^{i}, \text { if } \tau=l .
\end{array}\right.
$$

We further assume that the individual output to capital ratios given by $k^{i}$ are randomly distributed across the population of firms around the average value $k \in \mathbb{R}_{++}$, which for simplicity is taken to be an exogenous constant. Therefore, the conditional expected value of the profit rate $r_{t}$ associated with each type $\tau$ is given by:

$$
E\left(r_{t} \mid \tau\right)=\left\{\begin{array}{l}
\pi_{h}\left(\lambda_{t}\right) k, \text { if } \tau=h, \\
\pi_{\ell} k, \text { if } \tau=l .
\end{array}\right.
$$

Based again on the law of iterated expectations and the conditional expectation in (12), the short-run average profit rate in a given period $t, \bar{r}_{t}$, can be defined as the expected profit rate in the short run for a given frequency distribution of labor extraction compensation strategies across firms $\left(\lambda_{t}, 1-\lambda_{t}\right)$ :

$$
\begin{aligned}
\bar{r}_{t} \equiv E\left[E\left(r_{t} \mid \tau\right)\right] & =\lambda_{t} E\left[r_{t} \mid \tau=h\right]+\left(1-\lambda_{t}\right) E\left[r_{t} \mid \tau=\ell\right] \\
& =\left[\lambda_{t} \pi_{h}\left(\lambda_{t}\right)+\left(1-\lambda_{t}\right) \pi_{\ell}\right] k=\bar{\pi}\left(\lambda_{t}\right) k
\end{aligned}
$$

Therefore, as (10) and (13) imply that, in the short run, the average profit rate is a multiple of the average profit share, it follows that these two alternative profitability measures always move in the same direction. We can use (10) to evaluate how the short-run average profit share respond to a change in the frequency distribution of labor extraction strategies as measured by $\lambda_{t}$ :

$$
\frac{\partial \bar{\pi}\left(\lambda_{t}\right)}{\partial \lambda_{t}}=\pi_{h}\left(\lambda_{t}\right)-\pi_{\ell}+\lambda_{t} \frac{\partial \pi_{h}\left(\lambda_{t}\right)}{\partial \lambda_{t}} .
$$


Note that, for all $\lambda_{t} \in(0,1] \subset \mathbb{R}$, based on (8) we have:

$$
\frac{\partial \pi_{h}\left(\lambda_{t}\right)}{\partial \lambda_{t}}=-u_{\ell} w^{\lambda_{t}-\beta} \ln w<0
$$

Given that $\pi_{h}(\beta)-\pi_{\ell}=0$, we can infer from (14) and (15) that $\partial \bar{\pi} / \partial \lambda_{t}<0$ for all $\lambda_{t} \in(\beta, 1] \subset \mathbb{R}$. In the interval $[0, \beta) \subset \mathbb{R}$, however, we have $\pi_{h}\left(\lambda_{t}\right)-\pi_{\ell}>0$. Therefore, the sign of (14) along the whole interval in question requires further investigation.

Based on (7) and (8), we can re-write (14) as follows:

$$
\frac{\partial \bar{\pi}\left(\lambda_{t}\right)}{\partial \lambda_{t}}=u_{\ell}\left[\left(1-w^{\lambda_{t}-\beta}\right)-\lambda_{t} w^{\lambda_{t}-\beta} \ln w\right]
$$

And considering (16), we have:

$$
\frac{\partial \bar{\pi}(0)}{\partial \lambda_{t}}=u_{\ell}\left(1-w^{-\beta}\right)>0
$$

and:

$$
\frac{\partial \bar{\pi}(\beta)}{\partial \lambda_{t}}=-u_{\ell} \beta \ln w<0
$$

It the follows from (17) and (18) as well as the continuity of (16) that there is a frequency distribution of labor extraction strategies $\bar{\lambda} \in(0, \beta) \subset \mathbb{R}$ at which the following condition holds:

$$
\frac{\partial \bar{\pi}(\bar{\lambda})}{\partial \lambda_{t}}=u_{\ell}\left[\left(1-w^{\bar{\lambda}-\beta}\right)-\bar{\lambda} w^{\bar{\lambda}-\beta} \ln w\right]=0 .
$$

Moreover, it follows from (16) that:

$$
\frac{\partial^{2} \bar{\pi}\left(\lambda_{t}\right)}{\partial \lambda_{t}^{2}}=-u_{\ell} w^{\lambda_{t}-\beta}(\ln w)\left(2 \lambda_{t} \ln w\right)<0
$$

for all $\lambda_{t} \in[0,1] \subset \mathbb{R}$. Therefore, it follows from (20) that $\bar{\lambda} \in(0, \beta) \subset \mathbb{R}$ is unique, with the straightforward implication that $\partial \bar{\pi}\left(\lambda_{t}\right) / \partial \lambda_{t}>0$ for all $\lambda_{t} \in[0, \bar{\lambda}) \subset \mathbb{R}, \partial \bar{\pi}(\bar{\lambda}) / \partial \lambda_{t}=0$, and $\partial \bar{\pi}\left(\lambda_{t}\right) / \partial \lambda_{t}<0$ for all $\lambda_{t} \in(\bar{\lambda}, 1] \subset \mathbb{R}$. These properties are represented in Figure 2 .

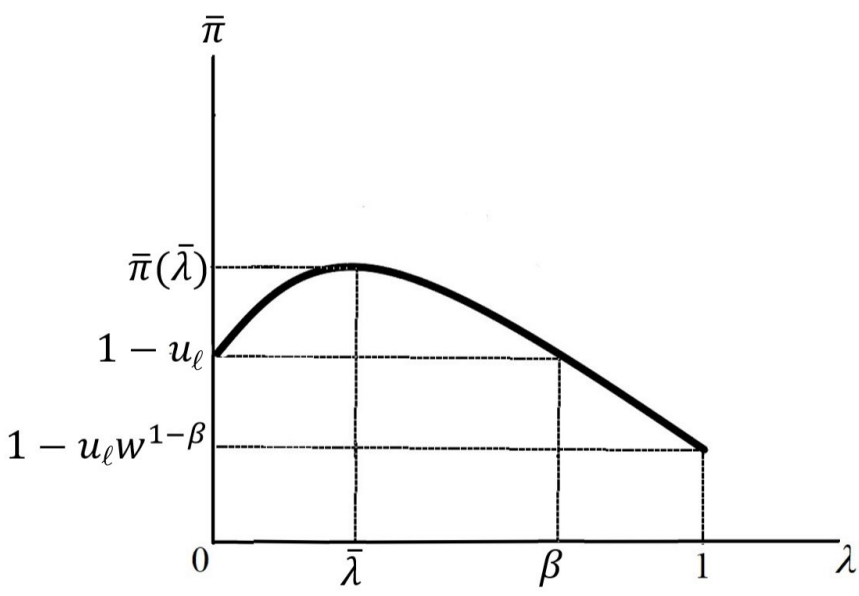

Figure 2: Average profit share as a function of the frequency distribution of labor extraction strategies

The economy is inhabited by two social classes: workers and firm-owner capitalists. Workers are 
always in excess supply owing to the continuing existence of an industrial reserve army of labor. Workers provide labor and are compensated with a higher (lower) conventional wage when they work for $h$-firms ( $\ell$-firms). In either case, all wage income is spent in consumption. Firm-owner capitalists, meanwhile, homogeneously save a fraction $\gamma \in(0,1) \subset \mathbb{R}$ of their profit income, which is the entire surplus over the respective wage bill. Given that capitalists save in order to fully finance their capital accumulation plans, and all profit income not consumed is automatically invested, firms face no realization (or effective demand) problems. As a result, innocuously assuming for simplicity that the individual capital stocks do not depreciate, the growth rate of the capital stock (and output) of the $i$-th firm of type $\tau$ can be expressed as:

$$
g_{\tau, t}^{i} \equiv \frac{S_{\tau, t}^{i}}{K_{\tau, t}^{i}}=\left\{\begin{array}{l}
\frac{\gamma R_{h, t}^{i}}{K_{h, t}^{i}}=\gamma \pi_{h}\left(\lambda_{t}\right) k^{i}, \text { if } \tau=h, \\
\frac{\gamma R_{\ell, t}^{i}}{K_{\ell, t}^{i}}=\gamma \pi_{\ell} k^{i}, \text { if } \tau=l,
\end{array}\right.
$$

where $S_{\tau, t}^{i}$ represents the savings of the $i$-th firm of type $\tau=h, \ell$.

Given that the individual output to capital ratios $k^{i}$ are randomly distributed across firms around the average value $k$, the conditional expected value of the growth rate of output $g_{t}$ in a given period $t$ for a type $\tau$ firm is as follows:

$$
E\left(g_{t} \mid \tau\right)=\left\{\begin{array}{l}
\gamma \pi_{h, t} k, \text { if } \tau=h, \\
\gamma \pi_{\ell} k, \text { if } \tau=l .
\end{array}\right.
$$

Using once again the law of iterated expectations and considering the conditional expected value of the growth rate of output in (22), we then establish the short-run average growth rate $\bar{g}_{t}$ in a given period $t$ as the expected growth rate of output in the short run for a given frequency distribution of labor extraction strategies in the population of firms $\left(\lambda_{t}, 1-\lambda_{t}\right)$ :

$$
\begin{aligned}
\bar{g}_{t} & =E\left[E\left(g_{t} \mid \tau\right)\right]=\lambda_{t} E\left(g_{t} \mid \tau=h\right)+\left(1-\lambda_{t}\right) E\left(g_{t} \mid \tau=l\right) \\
& =\gamma\left[\lambda_{t} \pi_{h}\left(\lambda_{t}\right)+\left(1-\lambda_{t}\right) \pi_{\ell}\right] k \equiv \bar{g}\left(\lambda_{t}\right),
\end{aligned}
$$

which considering (10) can then be re-written in the following way:

$$
\bar{g}\left(\lambda_{t}\right)=\gamma k \bar{\pi}\left(\lambda_{t}\right)
$$

Therefore, the short-run average growth rate of output in (24) depends on parametric constants in conjunction with the frequency distribution of labor extraction strategies. The latter (in conjunction with the resulting average profit share $\bar{\pi}\left(\lambda_{t}\right)$ ) is predetermined in the short run and endogenously timevarying in the transition from the short to the long run as governed by evolutionary dynamics to be described in the next section. Given the classical pedigree of the macroeconomic dynamic, which implies that output growth is driven by capital accumulation financed by the aggregate savings of firm-owner capitalists, the short-run average growth rate of output varies positively with the (homogeneous) saving propensity of firm-owner capitalists and the average profit share (and consequently the average profit rate $\left.k \bar{\pi}\left(\lambda_{t}\right)\right)$.

\section{Satisficing evolutionary dynamics}

The transition of the economy from the short to the long run is driven by exogenous changes in the available labor force, $N$, and endogenous changes in the frequency distribution of labor extraction 
strategies across firms, $\lambda_{t}$, and the aggregate stock of capital, $K$. While the latter increases over time due to savings-driven additions to the individual stocks of capital, $\left\{K^{i}\right\}_{i \in[0,1] \subset \mathbb{R}}$, we assume in a classical spirit that the growth rate of the available labor force is such that the industrial reserve army of labor is always replenished to an extent sufficient enough to avoid that labor becomes a constraint to capital accumulation. We simplify matters in an innocuous way by assuming that the available labor force grows endogenously at the same rate as capital accumulation, so that the capital to labor supply ratio remains constant.

The frequency distribution of labor extraction strategies across firms is endogenously time-varying as driven by evolutionary dynamics in the spirit of the contributions of Herbert Simon centered on the notion of satisficing choice. According to Simon (1959, 1978), reality is complicated relative to the information processing and decision making capacities of the individual. In this context, as elaborated by Simon (1955, 1956), satisficing theory conceives of choice as intending to meet an acceptability threshold rather than to select the best of all alternatives, with the effect that satisficing theory greatly contrasts with optimization theory. As suggested by Simon (1987), this contrast is analogous to 'looking for the sharpest needle in the haystack' (i.e., optimizing) versus 'looking for a needle sharp enough to sew with' (i.e., satisficing). In fact, given a probability density distribution of needles of varied degrees of sharpness throughout the haystack, the task of searching for the sharpest needle may demand effort proportional to the size of the haystack. Meanwhile, searching for a needle sharp enough to sew with demands an effort level that depends solely on the density of needles of the acceptable sharpness. In effect, experimental evidence on satisficing behavior as theorized by Simon $(1955,1956)$ is found in Caplin et al. (2011) and Hey et al. (2017).

Let us describe the satisficing evolutionary dynamics which yield the law of motion of the proportion of firms that follow the higher wage strategy in an attempt to extract labor from labor power more effectively. An individual $h$-firm $i$ takes its current profit rate given by (11) and compares it to the profit rate it considers acceptable or satisfactory, which is denoted by $\rho^{i}=\pi^{i} k^{i}$, where $\pi^{i}$ is the profit share associated with such acceptable or satisfactory profit rate, for a given respective $k^{i}$. Conceiving of $t$ as the current period, if $\pi_{h, t} k^{i}=r_{h, t}^{i} \geq \rho^{i}=\pi^{i} k^{i}$, this $h$-firm does not even consider changing its wage compensation strategy to extract labor from labor power in period $t+1$. Otherwise, if $r_{h, t}^{i}<\rho^{i}$, the $h$-firm $i$ in question then becomes a strategy reviser. The profit rate that is deemed acceptable or satisfactory by a given individual firm plausibly depends, inter alia, on a variety of idiosyncratic features, and we reasonably assume that such an acceptable or satisfactory profit rate is randomly and independently determined across firms and over time. Meanwhile, we assume that the profit share $\pi^{i}$ is a random variable with cumulative distribution $F:[0,1] \subset \mathbb{R} \rightarrow[0,1] \subset \mathbb{R}$, which is continuously differentiable and strictly increasing. Consequently, the probability of randomly choosing a firm $i$ in the subpopulation of $h$-firms which considers the current profit rate as unacceptable or unsatisfactory is given by:

$$
\operatorname{Pr}\left(\rho^{i}>r_{h, t}^{i}\right)=\operatorname{Pr}\left(\pi^{i}>\pi_{h, t}\right)=1-\operatorname{Pr}\left(\pi^{i} \leq \pi_{h, t}\right)=1-F\left(\pi_{h, t}\right) .
$$

Following Vega-Redondo (1996), we further assume that when such satisficing revision protocol transforms an individual $h$-firm $i$ into a potential strategy reviser that firm will switch to the alternative labor extraction strategy of offering the lower conventional wage with probability given by the proportion of firms which have previously followed such an alternative strategy. This is an imitation effect, which can be associated with the idea of an evolutionary switching protocol in the present setting of revisable choice of strategy to extract labor from labor power guided by satisficing criteria. Under this premise and further and plausibly assuming that the random variables related to the satisficing and imitation effects are independent from each other, the measure of $h$-firms which become $\ell$-firms is then given by: 


$$
\left.\lambda_{t}\left[1-F\left(\pi_{h}\left(\lambda_{t}\right)\right)\right]\left(1-\lambda_{t}\right)\right] .
$$

Analogously, the efflux from the subpopulation of $\ell$-firms which become $h$-firms is given by:

$$
\left(1-\lambda_{t}\right) \operatorname{Pr}\left(\rho^{i}>r_{\ell, t}^{i}\right) \lambda_{t}=\left(1-\lambda_{t}\right) \operatorname{Pr}\left(\pi^{i}>\pi_{\ell}\right) \lambda_{t}=\left(1-\lambda_{t}\right)\left[1-F\left(\pi_{\ell}\right)\right] \lambda_{t} .
$$

As a result, subtracting (26) from (27) yields an evolutionarily satisficing imitation dynamic represented by:

$$
\lambda_{t+1}-\lambda_{t}=\lambda_{t}\left(1-\lambda_{t}\right)\left[F\left(\pi_{h}\left(\lambda_{t}\right)\right)-F\left(\pi_{\ell}\right)\right] .
$$

Hence, assuming that $F(\cdot)$ is a strictly increasing function, a rise in the relative profit rate associated with the labor extraction strategy involving the payment of the higher wage in the current period leads to an increase in the proportion of firms adopting this strategy in the next period, whilst the opposite occurs when the relative profit rate associated with the labor extraction strategy featuring the payment of the lower wage rises. Therefore, the satisficing evolutionary dynamics in (28) reflect the operation of a selection protocol according to which the proportion of firms adopting a given wage compensation strategy to extract labor from labor power varies positively with the relative fitness (as measured by the relative profit rate) of such strategy. Given the contested nature of the labor exchange, as articulated in Bowles and Gintis $(1990,1993)$, a feature of the capitalist reality which is quite complicated relative to the limited information collection and processing as well as decision making capacities of the individual firm, the revisable choice of strategy to extract labor from labor power more effectively is inevitably doomed to be guided by satisficing instead of optimizing criteria.

As it turns out, the state transition of the economy is driven by the difference equation in (28), which has a state space given by $\Theta=\left\{\lambda_{t} \in \mathbb{R}: 0 \leq \lambda_{t} \leq 1\right\}$.

We will demonstrate that the satisficing evolutionary dynamic represented by (28) has two longrun equilibria featuring survival of only one labor extraction compensation strategy in each. These are monomorphic (pure-strategy) equilibria featuring no wage inequality (but differing levels of average wage rate and profit share across them). We will also demonstrate the possible existence of a third longrun equilibrium, now featuring the survival of both labor extraction strategies. This is a polymorphic (mixed-strategy) equilibrium featuring wage inequality.

Notice that $\lambda_{t+1}=\lambda_{t}=0$ for any $t \in\{0,1,2, \ldots\}$ readily satisfies (28). Therefore, one of the two monomorphic long-run equilibria of the system features the labor extraction strategy of compensating workers with the lower wage as the only survivor. In this monomorphic long-run equilibrium, it follows from (3) that the labor extraction (and hence labor productivity) differential takes the value of $\alpha_{t}=$ $w^{\beta+1}>1$ for all $t \in\{0,1,2, \ldots\}$.

Note now that $\lambda_{t+1}=\lambda_{t}=1$ for any $t \in\{0,1,2, \ldots\}$ also satisfies (28), so that the other monomorphic long-run equilibrium of the system features the labor extraction strategy of compensating workers with the higher wage as the only survivor. In this monomorphic long-run equilibrium, it follows from (3) that the labor extraction (and hence labor productivity) differential takes the value of $\alpha_{t}=w^{\beta} \in\left(1, w^{\beta+1}\right) \subset$ $\mathbb{R}$ for all $t \in\{0,1,2, \ldots\}$.

Meanwhile, the possible existence of a polymorphic equilibrium is defined by the condition $\lambda_{t+1}=$ $\lambda_{t}=\lambda^{*} \in(0,1) \subset \mathbb{R}$ for all $t \in\{0,1,2, \ldots\}$. Given that $F(\cdot)$ is continuous and strictly increasing, the satisfaction of such condition is equivalent to the equalization of the profit shares across labor extraction strategies (and hence in the population of firms). Considering (7) and (8), this long-run equilibrium with coexistence of both strategies to extract labor from labor power is obtained as follows: 


$$
\pi_{h}\left(\lambda^{*}\right)=\pi_{\ell} \Leftrightarrow 1-u_{\ell} w^{\lambda^{*}-\beta}=1-u_{\ell} \Leftrightarrow \lambda^{*}=\beta .
$$

When $\lambda_{t}=\lambda^{*}=\beta$, it follows from (3) that the labor extraction (and hence labor productivity) differential takes the value of $\alpha_{t}=w$. As expected, given that there is strategic substitutability in the adoption of the labor extraction mechanism featuring the payment of the higher wage, as represented in Figure 1, the labor extraction (and hence labor productivity) differential takes its highest (lowest) value when all firms compensate workers with the lower (higher) conventional wage, whilst it takes an intermediate value between these two extremes when both labor extraction strategies survive.

One noteworthy feature of the two monomorphic long-run equilibria is that, although the profit share becomes obviously equalized in the population of firms in either case, the same equalization does not apply to the profit rate due to the assumed heterogeneity in output to capital ratio across firms. In either case, however, the conditional expected value of the profit rate $r$ in (12) and the short-run average profit rate $\bar{r}$ in (13) nonetheless become equalized.

Moreover, although the stationarity condition associated with the polymorphic long-run equilibrium given by $\lambda_{t+1}=\lambda_{t}=\beta \in(0,1) \subset \mathbb{R}$ for all $t \in\{0,1,2, \ldots\}$ also does not imply equalization of the individual profit rates due to the assumed heterogeneity in output to capital ratio across firms, the conditional expected value of the profit rate $r$ given the type $\tau$ in (12) and the short-run average profit rate $\bar{r}$ in (13) nonetheless become equalized. In other words, the (uniform) expected profit rate associated with each one of the surviving strategies becomes equalized with the average profit rate.

Interestingly, therefore, although there is not equalization of individual profit rates across firms in either any of the two monomorphic equilibria or the unique polymorphic long-run equilibrium, there is both equalization of the individual expected profit rates in the population of firms and equalization of such uniform expected profit rate with the average profit rate in any long-run equilibrium.

The stability properties of these long-run equilibria can be properly investigated by means of the first-order Taylor approximation of (28) around $\lambda_{t}$, which is given by:

$$
\frac{\partial \lambda_{t+1}}{\partial \lambda_{t}}=1+\left(1-2 \lambda_{t}\right)\left[F\left(\pi_{h}\left(\lambda_{t}\right)\right)-F\left(\pi_{\ell}\right)\right]+\lambda_{t}\left(1-\lambda_{t}\right) F^{\prime}\left(\pi_{h}\left(\lambda_{t}\right)\right) \frac{\partial \pi_{h}\left(\lambda_{t}\right)}{\partial \lambda_{t}} .
$$

In the monomorphic long-run equilibrium with $\lambda_{t}=0$, the derivative in (30) becomes:

$$
\left.\frac{\partial \lambda_{t+1}}{\partial \lambda_{t}}\right|_{\lambda_{t}=0}=1+F\left(\pi_{h}(0)\right)-F\left(\pi_{\ell}\right) .
$$

Given from (7)-(8) that $\pi_{h}(0)-\pi_{\ell}=\left(1-w^{-\beta}\right) u_{\ell}>0$, which follows from our assumption that $\beta \in$ $(0,1) \subset \mathbb{R}$ and the economic meaningfulness condition that $u_{\ell} \in(0,1) \subset \mathbb{R}$, and since $F$ is a strictly increasing function, it follows that $F\left(\pi_{h}(0)\right)-F\left(\pi_{\ell}\right)>0$, so that the derivative in (31) is greater than one. Therefore, the monomorphic equilibrium featuring the labor extraction strategy of compensating workers with the lower wage as the only surviving strategy $(\lambda=0)$ is a local repulsor.

In the monomorphic long-run equilibrium with $\lambda_{t}=1$, the derivative in (30) now becomes:

$$
\left.\frac{\partial \lambda_{t+1}}{\partial \lambda_{t}}\right|_{\lambda_{t}=1}=1-\left[F\left(\pi_{h}(1)\right)-F\left(\pi_{\ell}\right)\right] .
$$

This derivative is also greater than one. In fact, as it follows from (7)-(8) that $\pi_{h}(1)-\pi_{\ell}=\left(1-w^{1-\beta}\right) u_{\ell}<$ 0 , given that $w>1, \beta \in(0,1) \subset \mathbb{R}$, and $u_{\ell} \in(0,1) \subset \mathbb{R}$, and since $F$ is a strictly increasing function, we have that $F\left(\pi_{h}(1)\right)-F\left(\pi_{\ell}\right)<0$, which implies that (32) is greater than one. Therefore, the monomorphic 


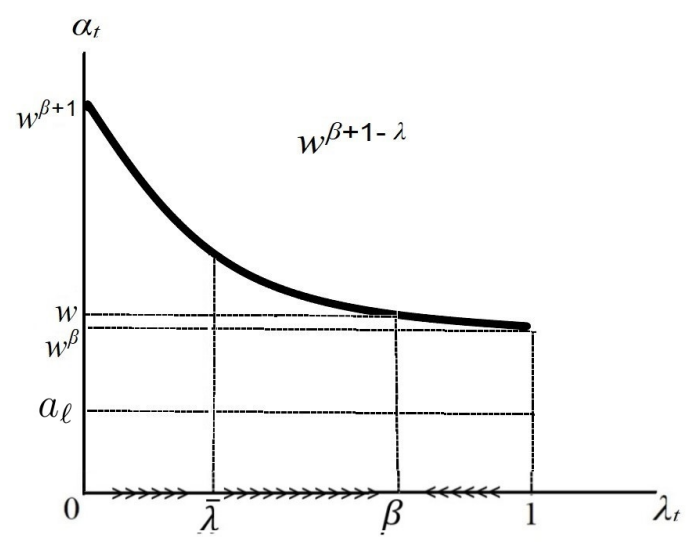

Figure 3: Labor extraction differential along the convergence path to the polymorphic long-run equilibrium

equilibrium featuring the labor extraction strategy of compensating workers with the higher wage as the only surviving strategy $(\lambda=1)$ is also a local repulsor.

Meanwhile, given (7)-(8) and (15), in the polymorphic long-run equilibrium with $\lambda_{t}=\lambda^{*}=\beta$, the derivative in $(30)$ becomes:

$$
\left.\frac{\partial \lambda_{t+1}}{\partial \lambda_{t}}\right|_{\lambda_{t}=\beta}=1+\beta(1-\beta) F^{\prime}\left(\pi_{h}(\beta)\right) \frac{\partial \pi_{h}(\beta)}{\partial \lambda_{t}}=1-\beta(1-\beta) F^{\prime}\left(1-u_{\ell}\right) u_{\ell} \ln w .
$$

The derivative above is smaller than one as $\beta(1-\beta) F^{\prime}\left(1-u_{\ell} w^{1-\beta}\right) u_{\ell} \ln w>0$. Therefore, this derivative can take any value between -1 and 1 , which means that the polymorphic long-run equilibrium with $\lambda_{t}=\lambda^{*}=\beta$ will be locally assimptotically stable, if the following condition is satisfied:

$$
\beta(1-\beta) F^{\prime}\left(1-u_{\ell} w^{1-\beta}\right) u_{\ell} \ln w<2 .
$$

If we assume that $F(\cdot)$ follows an uniform distribution with support $[0,1] \subset \mathbb{R}$, we can show that the interval of values of the wage differential $w=\frac{w_{h}}{w_{\ell}}$ for which the conditon (34) is satisfied is quite plausible. In order to show it, recalling that $F^{\prime}\left(1-u_{\ell} w^{1-\beta}\right)=1$, we can re-write (34) as follows:

$$
w<e^{\frac{2}{\beta(1-\beta) u_{\ell}}} \equiv \bar{w} .
$$

As the maximum value that the term $\beta(1-\beta)$ can take is $\beta=0.5$, even an extremely high value of the wage share in output of $h$-firms will generate an extremely high value of $\bar{w}$. For instance, for $\beta=0.5$ and $u_{\ell}=0.8$, we will obtain $\bar{w}=22026.5$. In this case, therefore, only an unreasonably high value of the wage differential $w=w_{h} / w_{\ell}$ will destabilize the polymorphic long-run equilibrium.

Let us now explore how the frequency distribution of labor extraction strategies and the labor extraction (or labor productivity) differencial interact along the convergence path to the polymorphic long-run equilibrium (as represented in Figure 3). As this interaction will crucially determine the dynamics of the average profit share along such convergence path (as represented in Figure 4), it will also ultimately determine the behavior of the rate of output growth in the long run.

When the initial value of the proportion of higher wage firms lies in the range given by $\lambda_{t} \in(0, \bar{\lambda}) \subset \mathbb{R}$, the convergence to the polymorphic long-run equilibrium involves an increasing proportion of such firms. 


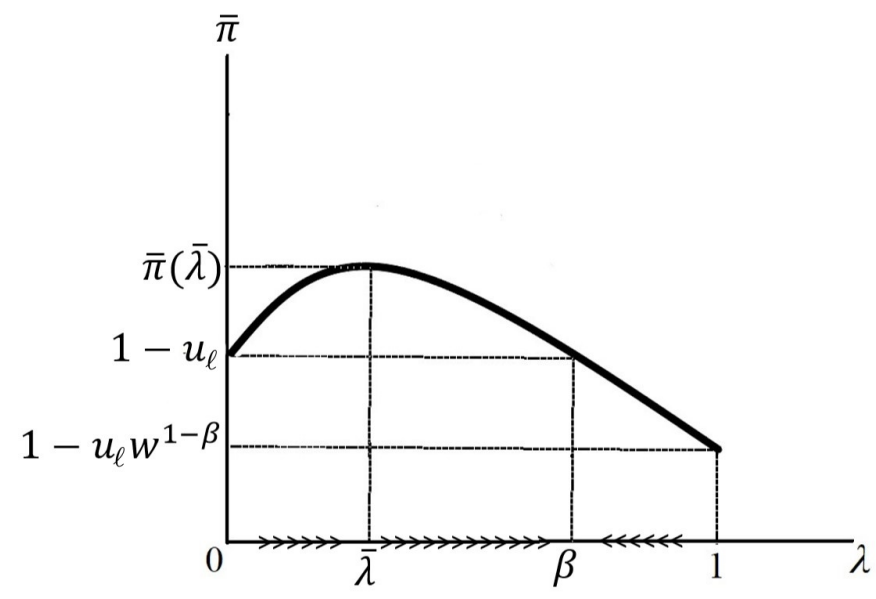

Figure 4: Average profit share along the convergence path to the polymorphic long-run equilibrium

Although this implies a falling labor extraction differential relative to lower wage firms, the average profit share and the rate of output growth are increasing and achieve their maximum values at the threshold given by $\bar{\lambda}$. When this threshold is crossed, the convergence to the polymorphic long-run equilibrium still involves an increasing proportion of such firms, but now the resulting additional fall in the labor extraction differential is enough to yield a falling average profit share and rate of output growth up to the completion of the convergence to the polymorphic long-run equilibrium.

This reversal in the behavior of the average profit share and the rate of output growth as the proportion of higher wage firms increases can be intuitively explained as follows. As represented in (14), a rise in the proportion of higher wage firms exerts two opposite effects on the average profit share for any $\lambda_{t} \in\left(0, \lambda^{*}\right) \subset \mathbb{R}$. The first is a positive composition effect arising from the fact that $\pi_{h}\left(\lambda_{t}\right)>\pi_{\ell}$ for any $\lambda_{t} \in\left(0, \lambda^{*}\right) \subset \mathbb{R}$, so that a rise in the proportion of higher wage firms will put an upward pressure on the average profit share. The second is a negative labor extraction effect associated with the fall in the labor productivity differential accruing (and hence in the profit share corresponding) to the higher wage strategy, so that a rise in the proportion of higher wage firms will also put a downward pressure on the average profit share. It turns out that the positive effect is stronger than the negative one when the proportion of $h$-firms is low enough $\left(0<\lambda_{t}<\bar{\lambda}\right)$, whilst the opposite takes place when $\bar{\lambda}<\lambda_{t}<\lambda^{*}$.

When $\lambda_{t} \in\left(\lambda^{*}, 1\right) \subset \mathbb{R}$, meanwhile, the convergence to the polymorphic long-run equilibrium involves a falling proportion of these firms. As represented in (14), this falling proportion of higher wage firms exerts two reinforcing positive effects on the average profit share for any $\lambda_{t} \in\left(\lambda^{*}, 1\right) \subset \mathbb{R}$. The first is a composition effect arising from the fact that $\pi_{h}\left(\lambda_{t}\right)<\pi_{\ell}$ for any $\lambda_{t} \in\left(\lambda^{*}, 1\right) \subset \mathbb{R}$ (and that is why the evolutionary dynamic is driving the proportion of $h$-firms down), so that a fall in the proportion of higher wage firms will put an upward pressure on the average profit share. The second is a labor extraction effect associated with the rise in the labor productivity differential accruing (and hence in the profit share corresponding) to the higher wage strategy, so that the falling proportion of higher wage firms when $\lambda_{t} \in\left(\lambda^{*}, 1\right) \subset \mathbb{R}$ exerts a double upward pressure on the average profit share. When $0<\lambda_{t}<\lambda^{*}$, therefore, the convergence to the polymorphic long-run equilibrium takes place with rising average rates of profit and output growth.

A few other features of the long-run dynamics of the system are noteworthy. First, given any initial heterogeneity in labor extraction compensation strategies across firms, and hence any initial wage inequality across workers, the economy eventually converges to a position at which the wage inequality (either higher or lower than initially) becomes permanent. Second, as represented in Figure 4, given any initial heterogeneity in labor extraction strategies across firms, the economy converges to a polymorphic 
long-run equilibrium at which the rate of output growth, although it is not at its lowest possible level, it is not at its highest possible level either. Or, to put it from the viewpoint of the functional distribution of income, the economy eventually converges to a polymorphic long-equilibrium in which the wage share, although it is not at its lowest possible level, it is not at its highest possible level either.

Third, the average profit share is the same either in the monomorphic long-run equilibrium with all firms following the labor extraction strategy of compensating workers with the lower wage or in the polymorphic long-run equilibrium. In principle, therefore, the long-run, permanent position could feature the same average wage share and average rates of profit and output growth as in the polymorphic equilibrium, but with no wage inequality, if all firms would follow the labor extraction strategy of compensating workers with the lower wage. However, such monomorphic long-run equilibrium featuring the lower wage strategy as the only survivor, unlike the polymorphic long-run equilibrium, is not eventually reachable if the economy does not happen to be there to begin with. The reason is that the satisficing evolutionary dynamics in (28) favors the survival of the labor extraction whose profitability (as measured by either the share of the rate of profit) is higher relative to the alternative strategy, and it happens that $\pi_{h}\left(\lambda_{t}\right)>\pi_{\ell}$ for any $0<\lambda_{t}<\lambda^{*}$.

Finally, leaving aside stability issues, it is far from obvious what long-run equilibrium configuration would be preferable to workers. By construction, unlike in the polymorphic equilibrium, there is not wage inequality in any of the two monomorphic equilibria. Moreover, the wage share is the highest in the monomorphic equilibrium with all firms following the higher wage strategy, and it is the same in the two other equilibria. Also by construction, the average conventional wage rises monotonically with the proportion of higher wage firms, so that it is also the highest in the monomorphic equilibrium with all firms following the higher wage strategy.

\section{Conclusions}

There is considerable evidence that labor intensity is endogenous to wage compensation and that inter- and intra-industry wage differentials across otherwise observationally equivalent workers are persistent. Against this backdrop, we explore the implications of firms periodically choosing between different wage compensation strategies to extract labor from labor power (and therefore obtain productivity from workers) more effectively. Reasonably, individual firms have bounded rationality, behave according to rules of thumb and revise their choice of wage compensation strategy having limited and localized knowledge concerning the system as a whole. Firms willing to extract more labor from labor power compensate workers with a higher instead of lower conventional wage, and the frequency distribution of these labor extraction strategies in the population of firms is driven by satisficing evolutionary dynamics in the spirit of the contributions of Herbert Simon that may generate wage inequality as long-run equilibrium.

The profit share accruing to firms that follow the labor extraction strategy of compensating workers with the higher wage varies negatively with the proportion of these firms. The intuition underlying this result is that there is strategic substitutability in the firms' choice of the higher wage strategy: the greater the proportion of higher wage firms, the smaller the differential between the higher conventional wage and the average conventional wage and, consequently, the smaller the positive labor extraction differential between higher wage and lower wage firms. Therefore, the negative payoff externality that a firm which decides to follow the higher wage strategy imposes on all the other higher wage firms can be suggestively interpreted as another contradiction of capitalism. Paraphrasing Kalecki's (1967) observation that capitalists do many things as a class, but they certainly do not invest as a class, we would suggest that capitalists do not choose strategy to extract labor from labor power as a class either. 
The satisficing evolutionary dynamics have two long-run equilibria featuring survival of only one wage compensation strategy in each. These are monomorphic (pure-strategy) equilibria featuring no wage inequality (but differing levels of average wage rate and profit share), but both are locally unstable. Under plausible conditions, and in accordance with the empirical evidence, there exists a third long-run equilibrium, now featuring the survival of both wage compensation strategies. This is a polymorphic (mixed-strategy) equilibrium featuring wage inequality which is locally stable under quite plausible conditions. Interestingly, although there is not equalization of individual profit rates across firms in either any of the two (certainly existing) monomorphic equilibria or the (possible) polymorphic longrun equilibrium, there is both equalization of the individual expected profit rates in the population of firms and equalization of such uniform expected profit rate with the average profit rate in any existing long-run equilibrium.

Finally, a larger proportion of firms following the labor extraction strategy of compensating workers with the higher wage does not necessarily result in a lower (higher) unit labor cost (profit share) and hence in higher average rates of profit and saving-determined output growth. The larger the proportion of firms that attempt to extract more labor from labor power by following the strategy of compensating workers with the higher wage, the less each of them succeeds, which is due to the existence of strategic substitutability in the firms' choice of the higher wage strategy. Given any initial heterogeneity in labor extraction strategies across firms, the economy converges to a polymorphic long-run equilibrium at which the average output growth rate, although it is not at its lowest possible level, it is not at its highest possible level either. Or, to put it from the viewpoint of the functional distribution of income, the economy eventually converges to a polymorphic long-equilibrium in which the average profit share, although it is not at its lowest possible level, it is not at its highest possible level either.

\section{References}

Abeler, J., Falk, A., Goette, L. and Huffman, D. (2011) Reference points and effort provision, The American Economic Review, 101(2), pp. 470-92.

Akerlof, G. (1982) Labor contracts as partial gift exchange, The Quarterly Journal of Economics, 87, pp. $543-69$.

Bellemare, C. and Shearer, B. (2009) Gift giving and worker productivity: Evidence from a firm-level experiment, Games and Economic Behavior, 67, pp. 233-244.

Bowles, S. (1985) The production process in a competitive economy: Walrasian, Neo-Hobbesian, and Marxian models, The American Economic Review, 75, 16-36.

Bowles, S. and Gintis, H. (1990) Contested exchange: New microfoundations of the political economy of capitalism, Politics and Society, 18, pp. 165-222.

Bowles, S. and Gintis, H. (1993) The revenge of homo economicus exchange and the revival of political economy, Journal of Economic Perspectives, 7, pp. 83-102.

Caju, P. D., Ktay, G., Lamo, A., Nicolitsas, D. and Poelhekke, S. (2010) Inter-industry wage differentials in E.U. countries: What do cross-country time varying data add to the picture? Journal of the European Economic Association, 8, pp. 478-86.

Campbell, C. M. and Kamlani, K. S. (1997) The reasons for wage rigidity: evidence from a survey of firms, The Quarterly Journal of Economics, 112(3), pp. 759-789. 
Caplin, A., Dean, M. and Martin, D. (2011) Search and satisficing, American Economic Review, 101(7), pp. 2899-2922.

Cappelli, P. and Chauvin, K. (1991) An interplant test of the efficiency wage hypothesis, The Quarterly Journal of Economics, 106(3), pp. 769-787.

Carruth, A., Collier, W. and Dickerson, A. (2004) Inter-industry wage differences and individual heterogeneity, Oxford Bulletin of Economics and Statistics, 66, pp. 811-846.

Charness, G. (2004) Attribution and reciprocity in an experimental labor market, Journal of Labor Economics, 22, pp. 665-688.

Charness, G. and Kuhn, P. (2007) Does pay inequality affect worker effort? Experimental evidence, Journal of Labor Economics, 25, pp. 693-723.

Clark, A. E., Masclet, D. Villeval. M. C. (2010) Effort and comparison income: Experimental and survey evidence, Industrial and Labor Relations Review, 63(3), pp. 407-426.

Dickens, W. and Katz, L. (1987) Inter-industry wage differences and industry characteristics. In: Kevin Lang and Jonathan Leonard (eds.) Unemployment and the Structure of Labor Markets, Oxford: Basil Blackwell, pp. 28-89.

Fehr, E. and Gächter, S. (2008) Wage differentials in experimental efficiency wage markets. In: Charles R. Plott and Vernon L. Smith (eds.) Handbook of Experimental Economics Results, Volume 1, Elsevier , pp. 120-126.

Gächter, S. and Christian, T. (2010) Social comparison and performance: Experimental evidence on the fair wage-effort hypothesis, Journal of Economic Behavior and Organization, 76, pp. 531-543.

Gintis, H. (1976) The nature of labor exchange and the theory of capitalist production, Review of Radical Political Economics, 8, pp. 36-54.

Gneezy, U. and List, J. (2006) Putting behavioral economics to work: Testing for gift exchange in labor markets using field experiments, Econometrica, 74(5), pp. 1365-1384.

Goldsmith, A. H., Veum, J. R. and Darity, Jr., W. (2000) Working hard for the money? Efficiency wages and worker effort, Journal of Economic Psychology, 21, pp. 351-385.

Greiner, B., Ockenfels, A. and Werner, P. (2011) Wage transparency and performance: A real-effort experiment, Economic Letters, 111, pp. 236-238.

Groshen, E. (1991) Sources of intra-industry wage dispersion: How much do employers matter? The Quarterly Journal of Economics, 106, pp. 869-884.

Hey, J. D., Permana, Y. and Rochanahastin, N. (2017) When and how to satisfice: an experimental investigation, Theory and Decision, 83(3), 337-353.

Jair da Silveira, J. and Lima, G. T. (2017) Employee Profit Sharing and Labor Extraction in a Classical Model of Distribution and Growth, Review of Political Economy, 29(4), 613-635.

Kalecki, M. (1967) The Problem of Effective Demand with Tugan-Baranovsky and Rosa Luxemburg. In: Selected Essays on the Dynamics of the Capitalist Economy, 1933-1970, Cambridge, UK: Cambridge University Press, 1971. 
Katz, L. (1986) Efficiency wage theories: A partial evaluation. In: Stanley Fischer (ed.) NBER Macroeconomics Annual, Cambridge, MA: MIT Press, pp. 235-276.

Katz, L. and Autor, D. (1999) Changes in the wage structure and earnings inequality. In: Orley C. Ashenfelter and David Card (eds.) Handbook of Labor Economics, Volume 3, Part A, Elsevier, pp. $1463-1555$.

Katz, L. and Summers, L. (1989) Industry rents: evidence and implications, Brookings Papers on Economic Activity: Microeconomics, 1989, pp. 209-275.

Krueger, A. and Summers, L. (1988) Efficiency wages and the inter-industry wage structure, Econometrica, 56, pp. 259-94.

Robinson, J. (1964) Economic Philosophy, London: Pelican Books.

Silveira, J. and Lima, G. (2016) Effort elicitation, wage differentials and income distribution in a wage-led growth regime, Metroeconomica, 67, pp. 44-75.

Simon H. A. (1955) A behavioral model of rational choice, The Quarterly Journal of Economics, 69, pp. 99-118.

Simon H. A. (1956) Rational choice and the structure of the environment, Psychological Review, 63, pp. $129-138$.

Simon, H.A. (1959) Theories of decision-making in economic and behavioral sciences, The American Economic Review, 49, 253-83.

Simon, H.A. (1978) Rationality as process and as product of thought, The American Economic Review, $68,1-16$.

Simon H. A. (1987) Satisficing, in: Eatwell J., Milgate, M. and Newman, P. (eds.) The New Palgrave: A Dictionary of Economics, Vol. 4, New York: Stockton Press.

Vega-Redondo, F. (1996) Evolution, Games and Economic Behaviour, Oxford, UK: Oxford University Press.

Weisskopf, T., Bowles, S. and Gordon, D. (1983) Hearts and minds: a social model of U.S. productivity growth, Brookings Papers on Economic Activity, 2, pp. 381-441. 